\title{
Descriptive Epidemiology of Multidrug Resistance Tuberculosis (MDR-TB) in Bangladesh
}

\author{
Abu Bakar Siddik1, Muhammad Maqsud Hossain'2, Sanjana Zaman³, Basana Marma4, \\ Gias Uddin Ahsan', Mohammad Rashed Uzzaman', Arman Hossain², \\ Mohammad Delwer Hossain Hawlader ${ }^{3 *}$
}

\author{
${ }^{1}$ School of Health and Life Sciences, North South University, Dhaka, Bangladesh \\ ${ }^{2}$ Genome Research Institute, North South University, Dhaka, Bangladesh \\ ${ }^{3}$ Department of Public Health, North South University, Dhaka, Bangladesh \\ ${ }^{4}$ Plan International Bangladesh, Dhaka, Bangladesh \\ ${ }^{5}$ School of Business and Economics, North South University, Dhaka, Bangladesh \\ Email: ^mohammad.hawlader@northsouth.edu
}

How to cite this paper: Siddik, A.B., Hossain, M.M., Zaman, S., Marma, B., Ahsan, G.U., Uzzaman, M.R., Hossain, A. and Hawlader, M.D.H. (2018) Descriptive Epidemiology of Multidrug Resistance Tuberculosis (MDR-TB) in Bangladesh. Journal of Tuberculosis Research, 6, 292-301. https://doi.org/10.4236/jtr.2018.64026

Received: October 29, 2018

Accepted: December 10, 2018

Published: December 13, 2018

Copyright (c) 2018 by authors and Scientific Research Publishing Inc. This work is licensed under the Creative Commons Attribution International License (CC BY 4.0).

http://creativecommons.org/licenses/by/4.0/

\begin{abstract}
Background: The number of reported MDR-TB cases has been increasing in recent years. Objectives: To describe the epidemiological profile of MDR-TB cases in Bangladesh. Design: This was a descriptive cross-sectional study. Settings: The study was conducted among the multi drug resistant tuberculosis patient admitted in the National Institute of Diseases of the Chest and Hospital (NIDCH) Dhaka, Bangladesh. Samples: 148 confirmed cases of MDR-TB. Materials and Methods: Hospital admitted MRD-TB cases were randomly chosen from the above mentioned hospital. Semi-structured and pretested questionnaire were introduced by researcher. Clinical and treatment data i.e. duration of TB drug intake, report of sputum, X-ray and blood test etc. were extracted from the hospital record. Results: Study found, majority of the participants (56.1\%) were in the age group of 16 - 30 years. $64.2 \%$ of the study subjects were married. Majority of the participants education were whether under primary or primary level. 24.3\% participant's family member and $14.5 \%$ of neighbor were having TB. Most common comorbidity were diabetes, pulmonary infection, hearing loss, psychiatric symptoms, chest pain, joint pain etc. $63.5 \%$ respondent had high degree of AFB for sputum positivity and more than $98 \%$ had positive finding in X-ray chest. On an average ESR was low and also few cases of extremely low ESR were found. $71.6 \%$ were under twenty four months regimen. Conclusion: We can conclude that, many possible factors for MDR-TB. There is an urgent need for
\end{abstract}


further study to confirm the exact factors in Bangladesh and address those immediately.

\section{Keywords}

MDR-TB, Risk Factors, Descriptive Study, Epidemiology, Bangladesh

\section{Introduction}

Tuberculosis (TB) is one of the leading causes of death worldwide [1]. It has been reported that, about 9 million people have developed tuberculosis and another 1.5 million people died due to TB across the globe in 2013 [2]. The number of reported MDR-TB cases has been increasing in recent years [3]. And it is estimated that incidence of MDR-TB is at least five times higher than the reported. In 2010, there were an estimated 13.7 million chronic active cases, 8.8 million new cases, and 1.5 million deaths occurred, mostly in developing countries [4] [5]. WHO has identified 27 high burden countries for MDR-TB, where Bangladesh is the sixth in rank [6] [7]. Four of those high burdened countries, including Bangladesh, belong to the South-East Asian region. In Bangladesh, MDR-TB is becoming an emerging public health problem [8].

According to the recent drug-resistant survey (DRS), 1.4\% of new cases and $29 \%$ of the retreatment cases in Bangladesh have MDR-TB [9]. Although the rate of MDR-TB is still relatively low, owing to the overall high TB burden in Bangladesh. However, the number of MDR-TB cases were quite high in 2013, which is 2100 new TB cases and 2600 previously treated TB cases [4]. Multi-drug-resistant tuberculosis (MDR-TB) is defined as tuberculosis that is resistant to at least one of Isoniazid (INH) or Rifampicin (RMP), the two most powerful first-line drugs for TB treatment [10]. MDR-TB cannot be treated with first-line anti-TB drugs and needs a longer treatment period with stronger second-line drugs [11]. MDR-TB has been described as a man-made problem resulting from the use of inadequate drug regimen that selects drug resistant tubercle bacilli, with several factors being linked to propagate its emergence [12] [13]. For example, previous history of TB treatment has been documented as an important risk factors that predicts emergence of MDR-TB [14]. When a patient resistant to one drug and takes a combination of two drugs including the one to which s/he is resistant, drug resistance to the second drug will emerge. Similarly, if a patient is resistant to two drugs, and takes those two drugs and a third drug only, then resistance to the third drug will emerge and so on; therefore a combination of poor compliance and poor medical supervision may result in MDR-TB [15]. All those information have been identified by developed country where laboratory investigations are up to the mark and hospital facilities are well established. However, the pattern of MRD-TB and its factors never have been identified among Bangladeshi population. That's why we aimed to identify the pattern and current status of MRD-TB among Bangladeshi population through this study. 


\section{Methodology}

This descriptive cross sectional study was conducted among the multi drug resistant tuberculosis patient admitted in the National Institute of Diseases of the Chest and Hospital (NIDCH) Dhaka, Bangladesh. This is the largest and highest level chest hospital of Bangladesh where referred patients come from all corner of the country. We recruited 148 hospital admitted MRD tuberculosis cases randomly from the above mentioned hospital. Semi-structured and pretested questionnaire were introduced to collect the data. Clinical and treatment data i.e. duration of TB drug intake, report of sputum, X-ray and blood test etc. were extracted from the hospital record. Those laboratory investigations were performed prior to the hospital admission and before start of MRD-TB treatment. Treatment category was done according to national TB control guideline of Bangladesh [16]. After collection, data were cleaned, coded and analyzed by the statistical software package IBM PASW Statistics version 23.0. Descriptive statistics were done to analyze the quantitative data. This study was approved by the ethical review committee of the department of public health, North South University (NSU). Informed written consent was obtained from the all participants before data collection.

\section{Results}

This hospital based descriptive type of cross sectional study was conducted in National Institute of Diseases of the Chest and Hospital (NIDCH) in Dhaka with a sample size of 148. A pre-tested modified interviewer administrated semistructured questionnaires were used to collect the information regarding socio-demographic factors, lifestyle factors, and clinical data. Out of a total of 148 respondents, female participants accounted $52.7 \%$. The age distribution of the participants showed majority of the participants (56.1\%) were in the age group of 16 - 30 years. Married participants constituted $64.2 \%$ of the study subjects and illiterates constituted $18.9 \%$. The proportion of subjects, who have completed primary education, under primary level, secondary school, higher secondary, undergraduate and graduate was $22.3 \%, 39.9 \%, 8.8 \%, 4.1 \%, 4.7 \%$ and $1.4 \%$ respectively. $73 \%$ had no smoking history and $93.9 \%$ had never consumed alcohol. Majority (58.1\%) of the participants had four to five members in their family, and most of them had one child (45.3\%) (Table 1).

Table 2 shows that, $24.3 \%$ participant's family member were also having TB. In terms of neighbor, $14.5 \%$ were also having TB. Most of the participants (48.6\%) didn't have diabetes, whereas $39.9 \%$ participant never tested diabetes and $11.5 \%$ participants had diabetes. That means, nearly everyone from the participants (89.2\%) didn't have diabetes or never tested before. $43.9 \%$ participants never tested pulmonary disease and $44.6 \%$ participants didn't have pulmonary disease of any type. Among the other diseases, $7.4 \%$ participants had hearing loss, $6.1 \%$ participants had psychiatric problem, $5.4 \%$ participants had chest pain, $2.7 \%$ participants had joint pain and $2 \%$ participants had eye disease. 
Table 1. Baseline characteristics of the study participants.

\begin{tabular}{|c|c|c|c|}
\hline Characteristics & Response & Number & Percent \\
\hline \multirow{2}{*}{ Sex } & Male & 70 & 47.3 \\
\hline & Female & 78 & 52.7 \\
\hline \multirow{5}{*}{ Age group (Years) } & $5-15$ & 5 & 3.4 \\
\hline & $16-30$ & 83 & 56.1 \\
\hline & $31-40$ & 30 & 20.3 \\
\hline & $41-55$ & 21 & 14.2 \\
\hline & $56-65$ & 9 & 6.1 \\
\hline \multirow{4}{*}{ Marital Status } & Single & 38 & 25.7 \\
\hline & Married & 95 & 64.2 \\
\hline & Divorced & 12 & 8.1 \\
\hline & Widowed & 3 & 2.0 \\
\hline \multirow{7}{*}{ Education of patient } & Under Primary & 59 & 39.9 \\
\hline & Primary & 33 & 22.3 \\
\hline & Secondary school & 13 & 8.8 \\
\hline & Higher Secondary & 6 & 4.1 \\
\hline & Undergraduate & 7 & 4.7 \\
\hline & Graduate & 2 & 1.4 \\
\hline & Illiterate & 28 & 18.9 \\
\hline \multirow{7}{*}{ Education of Patients spouse } & Under Primary & 25 & 16.9 \\
\hline & Primary & 36 & 24.3 \\
\hline & Secondary school & 14 & 9.5 \\
\hline & Higher Secondary & 4 & 2.7 \\
\hline & Undergraduate & 6 & 4.1 \\
\hline & Graduate & 1 & 0.7 \\
\hline & Illiterate & 24 & 16.2 \\
\hline \multirow{3}{*}{ History of Smoking } & Occasionally & 17 & 11.5 \\
\hline & Regularly & 23 & 15.5 \\
\hline & Never & 108 & 73.0 \\
\hline \multirow{3}{*}{ History of Alcohol Consumption } & Occasionally & 5 & 3.4 \\
\hline & Regularly & 4 & 2.7 \\
\hline & Never & 139 & 93.9 \\
\hline \multirow{4}{*}{ Family member } & One-Three & 10 & 6.8 \\
\hline & Four-Five & 86 & 58.1 \\
\hline & Six-Seven & 44 & 29.7 \\
\hline & More than Seven & 8 & 5.4 \\
\hline \multirow{4}{*}{ Number of children } & None & 48 & 32.4 \\
\hline & One & 67 & 45.3 \\
\hline & Two & 27 & 18.2 \\
\hline & Three & 6 & 4.1 \\
\hline
\end{tabular}


Table 2. Distribution of disease related factors of MDR TB.

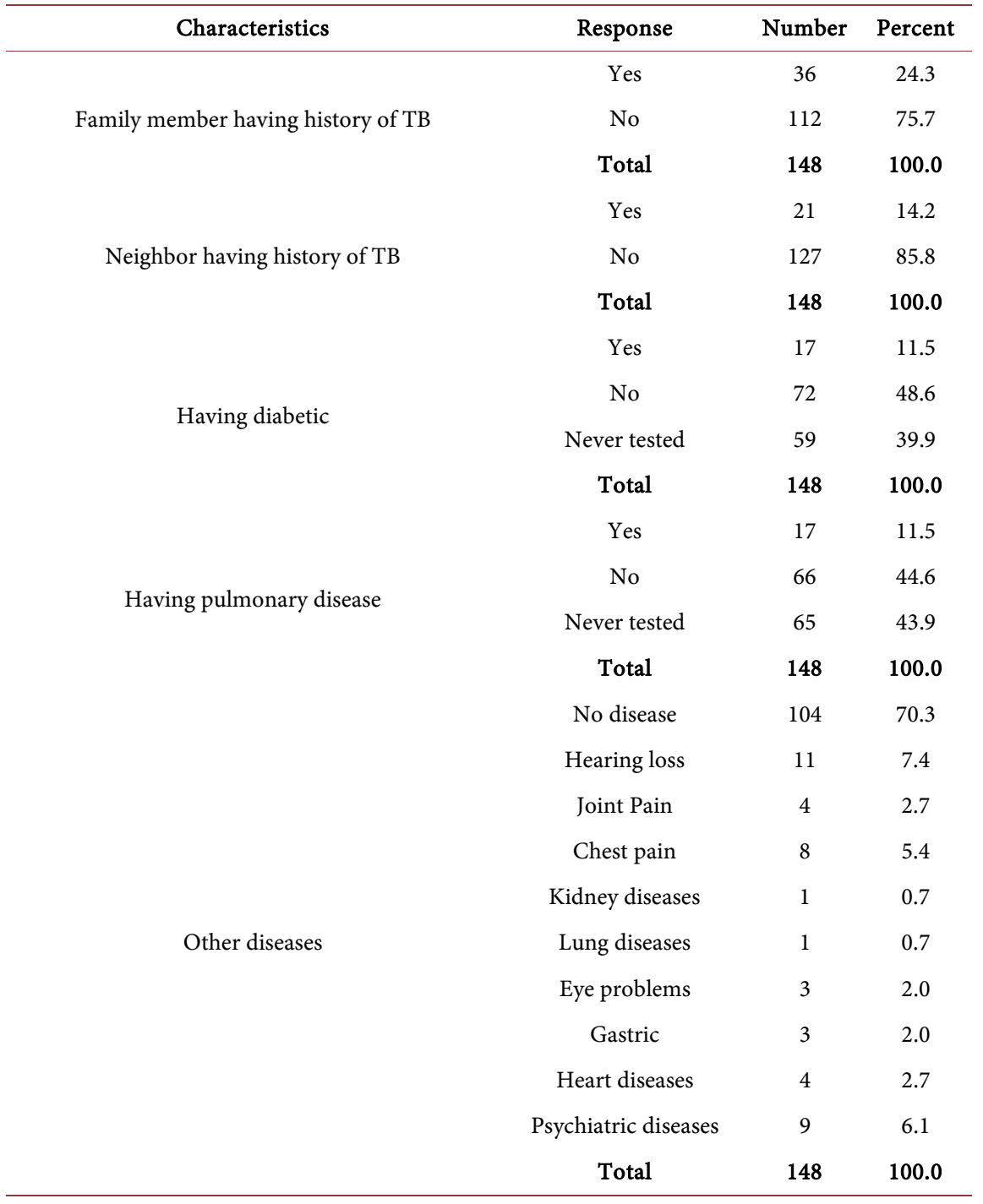

Table 3 shows that, majority of the patients (71.6\%) were taking TB drug of twenty four months (category III) regimen, 14.9\% respondent were taking six months (category I) regimen and $13.5 \%$ respondent were taking eight months (category II). Regarding sputum test results, 63.5\% respondents had high degree of sputum positivity (three plus) before treatment start, $18.9 \%$ respondent had moderate degree (two plus) and $16.2 \%$ had mild degree sputum positivity (one plus), only 2 cases had sputum test negative. X-ray chest of $98.6 \%$ patients shown positive findings, whereas only 2 cases found nothing in $\mathrm{x}$-ray. $25 \%$ participants have found mildly raised ESR level $(21-40 \mathrm{~mm}), 23 \%$ participants had moderately raised ESR level (41- $60 \mathrm{~mm}$ ), and 20.3\% participants had severely raised ESR (60 - $100 \mathrm{~mm})$. Most of the (60.1\%) participant's hemoglobin level was $11-20 \mathrm{gm} / \mathrm{dl}, 31.1 \%$ participant's hemoglobin level was moderately low (6 $10 \mathrm{gm} / \mathrm{dl})$ and $6.8 \%$ participant's hemoglobin level was extremely low $(0-5$ $\mathrm{gm} / \mathrm{dl}$ ). 
Table 3. Tuberculosis treatment and investigation related factors of MDR TB.

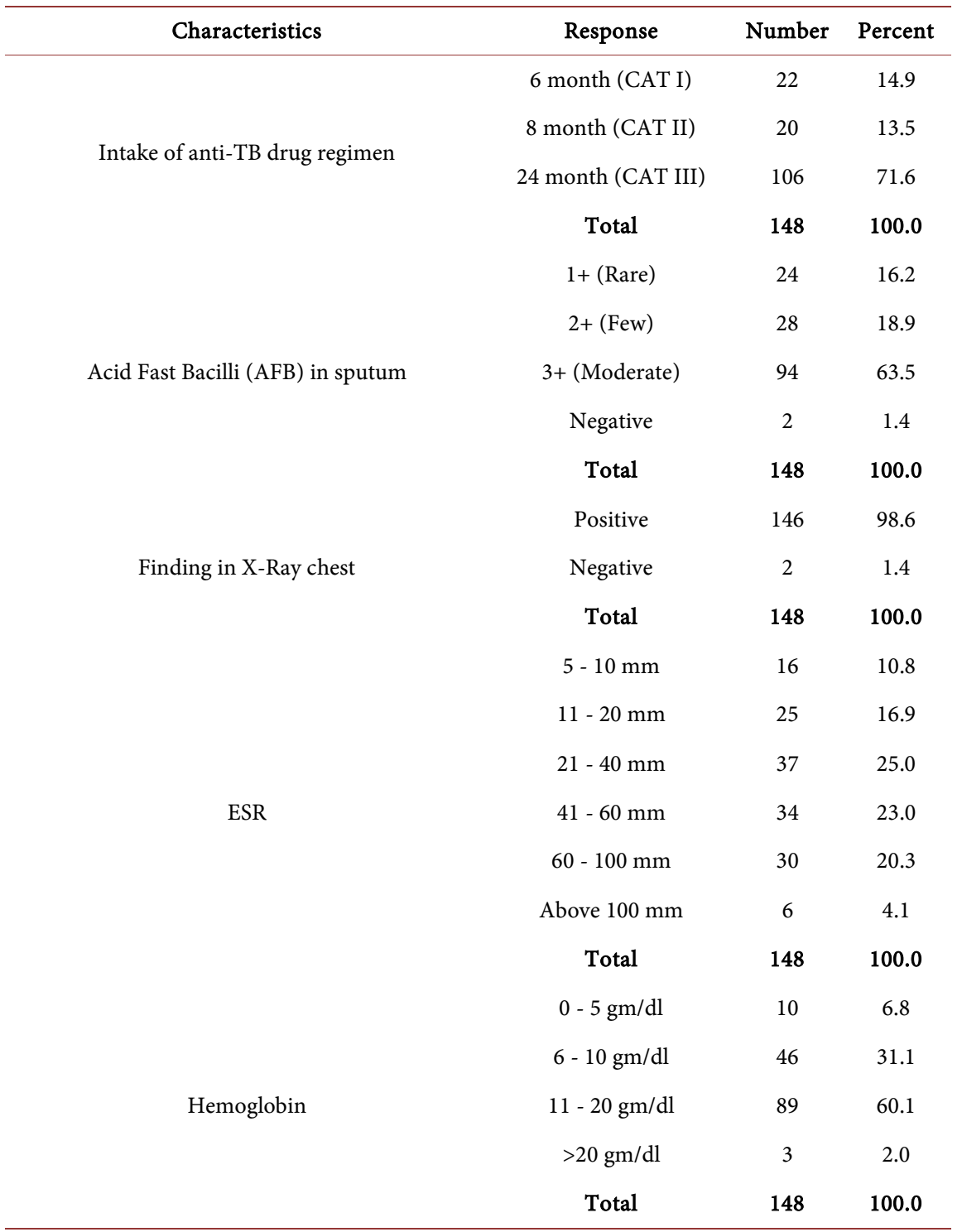

Table 4 shows the qualitative part of the study where different factors for developing MDR-TB and participant's knowledge related to MDR-TB were shortly described. It was found that a good number of the participants (77\%) were taking anti-TB drugs regularly. Whereas $23 \%$ participants didn't take medication regularly. $56.8 \%$ participants said doctor were giving them proper advice during anti-TB treatment course. $61.5 \%$ participants said that health worker visit their house regularly during anti-TB treatment course. Majority (60.8\%) of the participants took their drugs on appropriate time. Most (62.8\%) of the participants said they knew the consequence of missed dose of anti-TB drug. More than half (57.4\%) of the respondents responded they didn't have general knowledge about anti-TB drugs. Majority (89.2\%) of the participants aware of TB drug intake. Most $(83.8 \%)$ of the participants knew that the treatment can be taken free of cost from government. A good number (82.4\%) of the participants knew where 
Table 4. Knowledge and practice related factors of MDR TB treatment.

\begin{tabular}{|c|c|c|c|}
\hline Characteristics & Response & Number & Percent \\
\hline \multirow{2}{*}{ Take TB drugs regularly } & Yes & 114 & 77.0 \\
\hline & No & 34 & 23.0 \\
\hline \multirow{2}{*}{ Doctor provide proper advice during treatment } & Yes & 84 & 56.8 \\
\hline & No & 64 & 43.2 \\
\hline \multirow{2}{*}{ Health worker visit house regularly } & Yes & 91 & 61.5 \\
\hline & No & 57 & 38.5 \\
\hline \multirow[b]{2}{*}{ Take anti-TB drugs at appropriate time } & Yes & 90 & 60.8 \\
\hline & No & 58 & 39.2 \\
\hline \multirow{2}{*}{ Person knows the consequence of missing dose } & Yes & 93 & 62.8 \\
\hline & No & 55 & 37.2 \\
\hline \multirow{2}{*}{ General knowledge about drugs } & Yes & 63 & 42.6 \\
\hline & No & 85 & 57.4 \\
\hline \multirow{2}{*}{ Perception of TB drug intake } & Yes & 132 & 89.2 \\
\hline & No & 16 & 10.8 \\
\hline \multirow{2}{*}{ Patient knows that treatment cost is free } & Yes & 124 & 83.8 \\
\hline & No & 24 & 16.2 \\
\hline \multirow{2}{*}{ Patient knows that where to get the drugs } & Yes & 122 & 82.4 \\
\hline & No & 26 & 17.6 \\
\hline \multirow{2}{*}{ TV/Radio in house } & Yes & 110 & 74.3 \\
\hline & No & 38 & 25.7 \\
\hline \multirow{2}{*}{ Watch/hear TB related program } & Yes & 72 & 48.6 \\
\hline & No & 38 & 25.7 \\
\hline
\end{tabular}

to get the anti-TB drugs. Most (74.3\%) of the participants said they have either TV or radio in their house. Whereas $25.7 \%$ participants didn't have any TV or radio in their house. $48.6 \%$ participants said they either watched or heard TB related program. It seems overall knowledge among the MDR-TB patients was reasonably good but still lot of areas for improvement.

\section{Discussion}

Our study found that majority of the MDR-TB patients were adult. A recent study published in Ethiopia found the similar results [17]. In our study, most of the MDR-TB patients were married. A recently published paper from Somalia by Ali M.K. et al. found that married people have more success of TB treatment compared to unmarried people [18]. As we had only one group of participants, we did not see the association of MDR-TB with other factors. But we can assume that not only marital status but also general education and level of awareness is very important determinants for good outcome of any drugs regimen, and especially in the case of a longer duration treatment like tuberculosis. Majority of our 
participants education were either primary or under primary or even illiterate, that is another valuable determinants for compliance of anti-TB treatment. Previous study found strong association of treatment outcome with education [18] [19]. Not only patient's education, their spouse's also important contributing factors for treatment of TB. We again assume that, one of the important factors for MDR-TB of our patients was low education.

In our study, majority of the participants had large family, which might be one of the important factors of MDR-TB. Several recent studies have found that population structure and family size is an important factors for drug resistance [20] [21], even rate of TB infection is high among densely populated family [21]. And chance of repeated infection and co-infection also higher among the densely populated family [22]. Our study found that $24.3 \%$ family members and $14.2 \%$ neighbor were having tuberculosis, which are extremely important factors for MDR tuberculosis. Several previous studies indicated about those contributing factors among other social determinants [23] [24].

In this study, majority (71.6\%) of the patients were taking the regimen of 24 months and almost equal percentage were taking 6 months and 8 months regimen. Very recently, DR-TB Working Group of the International Union Against Tuberculosis and Lung Disease (The Union), in collaboration with RESIST-TB has launched an online survey to Union members around the world. Survey results showed the diversity in treatment roll-out: $36 \%$ respondents stated that their country is using the 9-month regimen for MDR-TB treatment; $41 \%$ are using bedaquiline and delamanid, but not the 9-month regimen; $28 \%$ are using both; and $22 \%$ of respondents indicated that their country does not currently offer either of these treatment options. Recent report of WHO recommended longer duration of MDR-TB regimens and the monitoring of therapeutic response using culture, along with many regimens for treating MDR-TB [25]. Since the present study was confined only to MDR-TB cases and there was no comparison group, definite conclusion regarding the risk factors may not be drawn but we could mention the proportion of some factors are higher among MDR-TB cases in our study.

\section{Conclusion}

Based on the findings from this present study, it is recommended to increase awareness among the family members of $\mathrm{TB}$ patients regarding the treatment regimen and duration of treatment. Strengthen the patient's supervision during continuous phase of anti-TB treatment might help to reduce the MDR-TB. Use of incentives, enhancing contact tracing, and increasing awareness regarding sputum disposal practices are also recommended for effective control of MDR-TB.

\section{Conflicts of Interest}

The authors declare no conflicts of interest regarding the publication of this paper. 


\section{References}

[1] Eker, B., Ortmann, J., Migliori, G.B., Sotgiu, G., Muettcrlcin, R., Centis, R., et al. (2008) Multidrug- and Extensively Drug-Resistant Tuberculosis, Germany. Emerging Infectious Diseases, 14, 1700-1706. https://doi.org/10.3201/eid1411.080729

[2] Zumla, A., George, A., Sharma, V., Herbert, R.H.N., of Ilton, B.M., Oxley, A., et al. (2015) The WHO 2014 Global Tuberculosis Report-Further to Go. The Lancet Global Health, 3, e10-e2. https://doi.org/10.1016/S2214-109X(14)70361-4

[3] World Health Organization (2014) Global Tuberculosis Report 2014. Geneva.

[4] World Health Organization. WHO Report 2011. Global Tuberculosis Control. http://apps.who.int/iris/bitstream/10665/44728/1/9789241564380_eng.pdf

[5] Fahmidul Haque, A.K.M., Khan, A., Lutfunnahar, B., Mukti, I.J., Islam, T., Chakma, S., et al. (2014) Assessment of Bangladeshi Mothers' Knowledge and Awareness on Childhood Tuberculosis: A Cross Sectional Study. Science Journal of Public Health, 2, 309-315.

[6] Bangladesh, TB Care-II, Funded by USAID, 2014. http://tbcare2.org/cp-bangladesh

[7] NTP. National Tuberculosis Control in Bangladesh. Annual Report 2007. National Tuberculosis Control Programme, DGHS, MOH\&FW. Dhaka, 2008.

[8] National TB Control Programme DGoHS, Bangladesh. Tuberculosis Control in Bangladesh. Annual Report. Dhaka, 2014.

[9] Kamal, S.M., Hossain, A., Sultana, S., et al. (2015) Anti-Tuberculosis Drug Resistance in Bangladesh: Reflections from the First Nationwide Survey. International Journal of Tuberculosis and Lung Disease, 19, 151-156. https://doi.org/10.5588/ijtld.14.0200

[10] Zumla, A., Abubakar, I., Raviglione, M., Hoelscher, M., Ditiu, L., McHugh, T.D., et al. (2012) Drug-Resistant-Tuberculosis-Current Dilemmas, Unasnswered Questions, Challenges and Priority Needs. The Journal of Infectious Diseases, 205, S228-S240. https://doi.org/10.1093/infdis/jir858

[11] World Health Organization (2011) Towards the Universal Access to Diagnosis and Treatment of Multidrug-Resistant and Extensively Drug-Resistant Tuberculosis by 2015, WHO Progress Report. WHO, Geneva.

[12] https://www.aphl.org/programs/infectious_disease/tuberculosis/TBCore/TBAssess mentTool.pdf

[13] Andrews, J.R., Shah, N.S., Weissman, D., Moll, A.P., Friedland, G. and Gandhi, N.R. (2010) Predictors of Multidrug and Extensively Drug-Resistant Tuberculosis in a High HIV Prevalence Community. PLoS One, 5, 1-6. https://doi.org/10.1371/journal.pone.0015735

[14] El Mahalli, A. and Al-Qahtani, M.F. (2015) Predictors of Drug Resistance in Tuberculosis Patients in the Eastern Province, Saudi Arabia. Journal of the Egyptian Public Health Association, 90, 24-28. https://doi.org/10.1097/01.EPX.0000461677.83722.78

[15] Tony, S.J., Elspeth, M.S. and Peter, D. (2010) Tuberculosis, Bronchiectasis and Chronic Airflow Obstruction. Respirology, 15, 623-628.

https://doi.org/10.1111/j.1440-1843.2010.01749.x

[16] http://www.ntp.gov.bd/item_view.php?news_detail=Guidelines

[17] Worku, Y., Getinet, T., Mohammed, S. and Yang, Z. (2018) Drug-Resistant Tuberculosis in Ethiopia: Characteristics of Cases in a Referral Hospital and the Implica- 
tions. International Journal of Mycobacteriology, 7, 167-172.

https://doi.org/10.4103/ijmy.ijmy_48_18

[18] Ali, M.K., Karanja, S. and Karama, M. (2017) Factors Associated with Tuberculosis Treatment Outcomes among Tuberculosis Patients Attending Tuberculosis Treatment Centres in 2016-2017 in Mogadishu, Somalia. Pan African Medical Journal, $28,197$.

[19] Di Gennaro, F., Pizzol, D., Cebola, B., Stubbs, B., Monno, L., Saracino, A., et al. (2017) Social Determinants of Therapy Failure and Multi Drug Resistance among People with Tuberculosis: A Review. Tuberculosis, 103, 44-51. https://doi.org/10.1016/j.tube.2017.01.002

[20] Zhao, Y., Feng, Q., Tang, K., Zhang, C., Sun, H. and Luo, T. (2012) The Population Structure of Drug-Resistant Mycobacterium Tuberculosis Clinical Isolates from Sichuan in China. Infection, Genetics and Evolution, 12, 718-724. https://doi.org/10.1016/j.meegid.2011.09.022

[21] Mohammadzadeh, Kh.A., Ghayoomi, A. and Maghsoudloo, D. (2016) Evaluation of Factors Associated with Failure of Tuberculosis Treatment under DOTS in Northern Islamic Republic of Iran. Eastern Mediterranean Health Journal, 22, 87-94. https://doi.org/10.26719/2016.22.2.87

[22] Chen, J., Cao, W., Chen, R., Ren, Y. and Li, T. (2016) Prevalence and Determinants of HIV in Tuberculosis Patients in Wuxi City, Jiangsu Province, China: A Cross-Sectional Study. International Journal of STD \& AIDS, 27, 1204-1212. https://doi.org/10.1177/0956462415612618

[23] Stosic, M., Vukovic, D., Babic, D., Antonijevic, G., Foley, K.L., Vujcic, I., et al. (2018) Risk Factors for Multidrug-Resistant Tuberculosis among Tuberculosis Patients in Serbia: A Case-Control Study. BMC Public Health, 18, 1114 https://doi.org/10.1186/s12889-018-6021-5

[24] Venkatesh, U., Srivastava, D.K., Srivastava, A.K. and Tiwari, H.C. (2018) Epidemiological Profile of Multidrug-Resistant Tuberculosis Patients in Gorakhpur Division, Uttar Pradesh, India. Journal of Family Medicine and Primary Care, 7, 589-595. https://doi.org/10.4103/jfmpc.jfmpc_99_17

[25] http://www.who.int/tb/areas-of-work/drug-resistant-tb/treatment/gdg-meeting-md r-rr-tb-treatment-2018-update/en/ 